\title{
Prevalence and Risk Factors of Fear of Falling among Elderly:
}

\section{A Review}

\section{Md Sazedur R*}

Khulna University, Bangladesh

*Corresponding author: Md. Sazedur Rahman, Statistics discipline, Khulna University, Khulna-9208, Bangladesh, Email: sazedur.stat@gmail.com

\section{Review Article \\ Volume 2 Issue 6}

Received Date: October 02, 2018

Published Date: November 12, 2018

DOI: $10.23880 / \mathrm{mjccs}-16000185$

\section{Abstract}

The world population is aging rapidly. Fear of falling among the elderly constitute a significant problem in health care. Among community-dwelling elderly, fear of falling is frequent, with prevalence ranging from $3 \%$ to $85 \% \%$ in community-based epidemiologic studies. The aim of this review is to reveal the prevalence and risk factors of fear of falling (FOF) among elderly. The review has identified that age, sex, physical performance, comorbidity, a history of falls, hearing impairment, poor self-related health and depressive symptoms affect fear of falling. The consequences that develop as a result of a fear of falling can include: loss of confidence, decreased quality of life, mobility or activity restriction and the development of deconditioning, leading to loneliness, depression, and anxiety, subsequent falls and physical, psychological and mental function declines. Maintenance of physical function and pain management might be important for older adults with fear of falling.

Key words: Fear of Falling; Elderly; Older Adults; Falls; Gerontology

\section{Introduction}

Falls among the elderly constitute a significant problem in health care [1]. Falls may also result in a post fall syndrome that includes dependence, loss of autonomy, confusion, immobilization and depression $[1,2]$. Fall-induced injuries are increasing more rapidly than can be accounted for by the in-crease in the elderly population. Fall causes considerable costs as well as physical and social costs [3]. Elderly people are more prone to unpredictable and unexpected falls. Falls are common in elderly people and the risk of falling increases with increasing age [4].
Falls have serious consequences on both physical functioning and quality of life among senior citizens [5]. Individuals who experience a fall may go on to develop fear of falling. According to Tinetti, et al. $48 \%$ of those over the age of 75 who had fallen in the previous year had a fear of falling [6]. Moreover, it has been noted that among individuals who fall, there is a high percentage $(3 \%-85 \%)$ who have a fear of falling [3,7]. It is also known that fear of falling is present in older adults who have never fallen have a fear of falling [8]. Fear of falling, whether or not related to a previous fall, can have a major impact on older adults. Fear of falling is associated with 


\section{Medical Journal of Clinical Trials \& Case Studies}

functional impairment which leads to loneliness and depression [9].

Fear of falling is more complicated which refers a person's belief in their own ability to perform a task safely, without losing balance. Some researchers have stated it as patient's loss of confidence in one's balance abilities. Tinetti and Powell defined fear of falling as a continuous worry about falling that at last restricted them of daily activities [6]. By Tidieksaar, fear of falling indicates an unsound avoidance of movement because of fear of falling [10]. Many people defined fear of falling in different ways. To someone it includes avoidance of daily activities and to another's it is the loss of confidence in balance and walking. Age, sex, physical performance, comorbidity, a history of falls, hearing impairment, poor self-related health and depressive symptoms affect fear of falling [11,12]. The individuals with fear of falling diminish their world, resulting in social isolation and ultimately psychological decline.

\section{Prevalence and Risk Factors of Fear of Falling}

Among community-dwelling elderly, fear of falling is frequent, with prevalence ranging from $3 \%$ to $85 \% \%$ in community-based epidemiologic studies $[3,7,13]$. Elderly individuals who have actually fallen have reported prevalence rates of fear of falling is $29 \%$ to $95.2 \%$ whereas $33-46 \%$ of community-dwelling older adults who have not fallen also reported fear of falling [13,1517]. The prevalence of fear of falling has been found nearly $46 \%$ in nursing home residents, $47 \%$ of persons with dizziness and a-third among hospitalized elderly patients without a specific diagnosis [18-20]. More than two-third elderly having fear of falling acknowledged avoiding daily activities because of this fear $[9,14]$. The prevalence of fear of falling among elderly reported as $76.6 \%$ in Korea, $53.4 \%$ in Taiwan, $33 \%-60 \%$ in USA $57.9 \%$ in Japan [21-24]. In some cases, individuals become housebound and isolated as a result of their fear [14].

The prevalence of fear of falling has been associated with differences in population characteristics, such as age distribution, fall history, frailty, or culture [25]. In many studies increased age has been linked to increase in the fear of falling [12,22,26,27]. But, Lavedán, Ana, et al. did not find significant correlation between age and fear of falling [28]. In addition, female gender were regularly more likely to be fearful of falls compared to male counterparts in several studies $[3,9,29]$. According to
Thiamwong, Ladda, and JomSuwanno, female gender are 1.87 times higher risk of fear of falling than male gender [30]. Having had a previous fall was associated with a fear of falling although there is also some evidence that it is not always a consequence of a past fall [20,31-33]. However, fear of falling itself is a risk factor of future falls $[31,33,34]$.

Physical performance significantly affect fear of falling $[35,36]$. Elderly with lower alleged physical status are more liable to have a fear of falling [26]. Yang, Nan-Ping, et al. found that fear of falling in older adults is more prevalent among elderly with cardiovascular diseases, diabetes mellitus, stroke [37]. Disable people have found more likely to develop fear of falling compared to normal individuals [31].

Having fewer social interaction or loneliness and depressive disorders also reported as risk factor of fear of falling $[9,14,26,38,39]$. Elderly with a symptom of some degree of depression have 2.2 times increased risk of falls [39]. One study found that fallers with a fear of falling were significantly more likely to score above 11 on the Geriatric Depression Scale [40]. This score is frequently used as a cut-off point to indicate mild or more severe depression, raising the possibility that minor or major depressive disorders may be more prevalent among fearful than non- fearful fallers. Another risk factors of fear of falling are: lower educational level, visual impairment, a sedentary lifestyle, and no available emotional support $[35,41]$.

Howland and colleagues (1998) examined factors associated with fear of falling and the effect of fear of falling on curtailing activities with a sample survey $(\mathrm{N}=266)$ of older adults living in public senior housing in Massachusetts [14]. They revealed that $55 \%$ of participants were afraid of fear of falling and of those who were afraid, $56 \%$ had curtailed activity because of this fear. Using logistic regression, they found being female, having had previous falls, and having fewer social contacts were significantly associated with fear of falling. Elderly with fear of falling, those who curtailed activities had significantly greater fear of falling from those who did not curtail activities regardless if slightly, somewhat, or very fearful of falling. Fall history appeared as an important contributor to fear of falling, whereas the impact of this fear on activities appeared more a function of social support. Their findings suggested different strategies for fear of falling prevention. 


\section{Medical Journal of Clinical Trials \& Case Studies}

Chang, Hsiao-Ting, Hsi-Chung Chen, and Pesus Chou (2016) on their "Factors associated with fear of falling among community-dwelling older adults in the Shih-Pai study in Taiwan" reported that the prevalence of fear of falling was $53.4 \%$. The rate of fear of falling was higher in female subjects. Falls in the previous 12-months, older age, insomnia, depression and worse subjective health were correlates of fear of falling for both sexes. Medical help in an emergency, diabetes mellitus and stroke in men and cardiovascular diseases in women were associated with fear of falling. The study was conducted in Taiwan among 3824 older adults aged $\geq 65$ years using structured questionnaire, including quality of life by using ShortForm 36, and information of fear of falling, fall history, demographics, medical conditions, insomnia, sleep quality, depression and subjective health through face-toface interviews [22].

Grenier, Sébastien, et al. (2018) conducted a study entitled "The association between fear of falling and motor imagery abilities in older community-dwelling individuals" to investigate whether the fear of falling is a cause of falls, a consequence, or both in communitydwelling adults aged $\geq 75$ years old with a sample of 640 individuals. Socio-demographic data, health status, history of falls and fear of falling were assessed at baseline and at two-year study period. In this study, the prevalence of falls at baseline was $25 \%$ as opposed to $35.2 \%$ at two-year. The prevalence of the fear of falling was $41.5 \%$ at baseline. They used logistic regression and found a significant association between a history of falls and the fear of falling. Other factors associated with the fear of falling were female gender, comorbidity, depressive symptoms, and disability. In total, $41.7 \%$ of the subjects who had reported a fear of falling at baseline had suffered at least one fall 2-year later. In addition, fear of falling was revealed as a risk factor for falls by unadjusted Cox regression analysis. According to the final model adjusted for other covariates, the only reliable predictor was female gender. However, the Cox model stratified by gender failed to show a crude association between fears of falling and falls [24].

Tomita, Yoshihito, et al. (2018) conducted a study namely "Prevalence of fear of falling and associated factors among Japanese community-dwelling older adults" based on 844 older adults (male, $n=350$; female, $n=494$ ) aged 60 to 92 years. They found the prevalence of fear of falling was $26.9 \%$ and $43.3 \%$ among the men and women, respectively. Multivariate logistic regression analysis identified in men, advanced age, falls in the previous year and pain and in women advanced age, longer 5 times chair stand times, falls in the previous year and pain were independently associated with fear of falling [12].

\section{Consequences of Fear of Falling}

Fear of falling is more complicated than it sounds. A fear of falling involves real anxiety and can result in physical sensations associated with fear, such as nausea and palpitations. Fear of falling is a fundamental health problem among community-dwelling older adults. A fear of falling leads older people to minimize their daily activities that they have the ability to perform $[10,14]$. This restriction of activity often leads to a loss of lower limb strength, a further reduction in mobility and physical function and loneliness. The consequences that develop as a result of a fear of falling can include: loss of confidence, decreased quality of life $[21,45]$ mobility or activity restriction and the development of deconditioning, leading to loneliness, depression, and anxiety, subsequent falls and physical, psychological and mental function declines [3,14,31,35,43-45]. Maintenance of physical function and pain management might be important for older adults with fear of falling. Several authors reported that exercise programs, including strength training, balance, endurance, mobility, and Tai-Chi programs decrease fear of falling in older adults [39,46-48].

\section{Conclusions}

FOF is a major health problem among the elderly population. This review identified a high prevalence of fear of falling among older adults. It prevails in older adults with and without the history of falls. FOF represents a significant threat to socialization, independence and morbidity or mortality. Knowledge of risk factors of FOF may be useful in developing multidimensional strategies to decrease it and improve the quality of life of elderly. Some potentially modifiable risk factors including age, female gender, fall history, having illness, visual problem, depression and loneliness associated with FOF have been identified in the present review. Maintenance of physical function and exercise programs, including strength training, balance, endurance, mobility, and Tai-Chi programs might decrease fear of falling in older adults. Successful management of FOF requires a combined and concerted effort on the part of the treating team. Finally, as an emerging problem, researchers should give more and wide emphasis on fear of falling research. 


\section{Medical Journal of Clinical Trials \& Case Studies}

\section{References}

1. Walker JE, Howland J (1991) Falls and fear of falling among elderly persons living in the community: occupational therapy interventions. American Journal of Occupational Therapy 45(2): 119-122.

2. Painter JA, Allison L, Dhingra P, Daughtery J, Cogdill K, et al. (2012) Fear of falling and its relationship with anxiety, depression, and activity engagement among community-dwelling older adults. American Journal of Occupational Therapy 66(2): 169-176.

3. Scheffer AC, Schuurmans MJ, Van Dijk N, Van Der Hooft T, De Rooij SE (2008) Fear of falling: measurement strategy, prevalence, risk factors and consequences among older persons. Age Ageing 37(1): 19-24.

4. Gale CR, Cooper C, Aihie Sayer A (2016) Prevalence and risk factors for falls in older men and women: The English Longitudinal Study of Ageing. Age Ageing 45(6): 789-794.

5. Cesari M, Landi F, Torre S, Onder G, Lattanzio F, et al. (2002) Prevalence and risk factors for falls in an older community-dwelling population. J Gerontol A Biol Sci Med Sci 57(11): M722-M726.

6. Tinetti ME, Powell L (1993) Fear of falling and low self-efficacy: a cause of dependence in elderly persons. J Gerontol 48: 35-38.

7. Kapella MC, Larson JL, Covey MK, Alex CG (2011) Functional performance in chronic obstructive pulmonary disease declines with time. Med Sci Sports Exerc 43(2): 218-224.

8. Jung D (2008) Fear of falling in older adults: Comprehensive review. Asian Nurs Res 2(4): 214222.

9. Arfken CL, Lach HW, Birge SJ, Miller JP (1994) The prevalence and correlates of fear of falling in elderly persons living in the community. Am J Public Health 84(4): 565-570.

10. Tideiksaar R (2002) Falling in Older People: Prevention and Management. $3^{\text {rd }}$ (Edn.), NewYork: Springer.

11. Malini FM, Lourenço RA, Lopes CS (2016) Prevalence of fear of falling in older adults, and its associations with clinical, functional and psychosocial factors: The Frailty in Brazilian Older People-Rio de Janeiro Study. Geriatr Gerontol Int 16(3): 336-344.

12. Tomita Y, Arima K, Tsujimoto R, Kawashiri SY, Nishimura T, et al. (2018) Prevalence of fear of falling and associated factors among Japanese communitydwelling older adults. Medicine 97(4): e9721.

13. Mann R, Birks Y, Hall J, Torgerson D, Watt I (2005) Exploring the relationship between fear of falling and neuroticism: a cross-sectional study in communitydwelling women over 70. Age and Ageing 35(2): 143147.

14. Howland J, Peterson EW, Levin WC, Fried L, Pordon D, et al. (1993) Fear of falling among the communitydwelling elderly. J Aging Health 5(2): 229-243.

15. Cruz DT, Duque RO, Leite IC (2017) Prevalence of fear of falling, in a sample of elderly adults in the community. Revista Brasileira de Geriatria e Gerontologia 20(3): 309-318.

16. Downton JH, Andrews K (1990) Postural disturbance and psychological symptoms amongst elderly people living at home. International Journal of Geriatric Psychiatry 5(2): 93-98.

17. Maki BE, Holliday PJ, Topper AK (1991) Fear of falling and postural performance in the elderly. Journal of gerontology 46(4): M123-M131.

18. Franzoni S, Rozzini R, Boffelli S, Frisoni GB, Trabucchi $M$ (1994) Fear of falling in nursing home patients. Gerontology 40(1): 38-44.

19. Burker EJ, Wong H, Sloane PD, Mattingly D, Preisser J, et al. (1995) Predictors of fear of falling in dizzy and nondizzy elderly. Psychology Aging 10(1): 104-110.

20. Gillespie LD, Robertson MC, Gillespie WJ, Sherrington C, Gates S, et al. (2012) Interventions for preventing falls in older people living in the community. Cochrane database of systematic reviews Issue 9.

21. Kim S, So WY (2013) Prevalence and correlates of fear of falling in Korean community-dwelling elderly subjects. Exp Gerontol 48(11): 1323-1328.

22. Chang HT, Chen HC, Chou P (2016) Factors associated with fear of falling among community-dwelling older 


\section{Medical Journal of Clinical Trials \& Case Studies}

adults in the Shih-Pai study in Taiwan. PloS one 11(3): e0150612.

23. Hanlon JT, Landerman LR, Fillenbaum GG, Studenski $\mathrm{S}$ (2002) Falls in African American and white community-dwelling elderly residents. J Gerontol A Biol Sci Med Sci 57(7): M473-M478.

24. Grenier S, Richard-Devantoy S, Nadeau A, Payette MC, Benyebdri F, et al. (2018) The association between fear of falling and motor imagery abilities in older community-dwelling individuals. Maturitas 110: 1820.

25. Hong I, Simpson AN, Logan S, Woo HS (2016) Longitudinal trends in fall accidents in community dwelling Korean adults: The 2008-2013 Korean community health survey. Annals of rehabilitation medicine 40(4): 657-665.

26. de Souza Moreira B, Sampaio RF, Diz JB, de Carvalho Bastone A, Ferriolli E, et al. (2017) Factors associated with fear of falling in community-dwelling older adults with and without diabetes mellitus: findings from the Frailty in Brazilian Older People Study (FIBRA-BR). Experimental gerontology 89: 103-111.

27. Bertera EM, Bertera RL (2008) Fear of falling and activity avoidance in a national sample of older adults in the United States. Health Soc work 33(1): 54-62.

28. Lavedán A, Viladrosa M, Jürschik P, Botigué T, Nuín C, et al. (2018) Fear of falling in community-dwelling older adults: A cause of falls, a consequence, or both? PLoS one 13(3): e0194967.

29. Payette MC, Belanger C, Léveillé V, Grenier S (2016) Fall-related psychological concerns and anxiety among community-dwelling older adults: Systematic review and meta-analysis. PLoS one 11(4): e0152848.

30. Thiamwong L, Suwanno J (2017) Fear of Falling and Related Factors in a Community-based Study of People 60 Years and Older in Thailand. International Journal of Gerontology 11(2): 80-84.

31. Friedman SM, Munoz B, West SK, Rubin GS, Fried LP (2002) Falls and fear of falling: which comes first? A longitudinal prediction model suggests strategies for primary and secondary prevention. Journal of the American Geriatrics Society 50(8): 1329-1335.
32. Suzuki M, Ohyama N, Yamada K, Kanamori M (2002) The relationship between fear of falling, activities of daily living and quality of life among elderly individuals. Nursing \& health sciences 4(4): 155-161.

33. Payette MC, Belanger C, Léveillé V, Grenier S (2016) Fall-related psychological concerns and anxiety among community-dwelling older adults: Systematic review and meta-analysis. PLoS one 11(4): e0152848.

34. Palagyi A, Rogers K, Meuleners L, McCluskey P, White A, et al. (2016) 496 Falls and cataract: investigating risk and predictors in older adults during their wait for surgery. Injury Prevention 22(S2): A179-A180.

35. Murphy SL, Williams CS, Gill TM (2002) Characteristics associated with fear of falling and activity restriction in community-living older persons. J Am Geriatr Soc 50(3): 516-520.

36. Deshpande N, Metter EJ, Lauretani F, Bandinelli S, Guralnik J, et al. (2008) Activity restriction induced by fear of falling and objective and subjective measures of physical function: a prospective cohort study. J Am Geriatri Soc 56(4): 615-620.

37. Yang NP, Hsu NW, Lin $\mathrm{CH}$, Chen HC, Tsao HM, et al. (2018) Relationship between muscle strength and fall episodes among the elderly: the Yilan study, Taiwan. BMC Geriatr 18(1): 90.

38. Austin N, Devine A, Dick I, Prince R, Bruce D (2007) Fear of falling in older women: a longitudinal study of incidence, persistence, and predictors. J Am Geriatr Soc 55(10): 1598-1603.

39. Clemson L, Kendig H, Mackenzie L, Browning C (2015) Predictors of injurious falls and fear of falling differ: an 11-year longitudinal study of incident events in older people. J Aging Health 27(2): 239-256.

40. Korpelainen R, Korpelainen J, Heikkinen J, Väänänen K, Keinänen-Kiukaanniemi S (2006) Lifelong risk factors for osteoporosis and fractures in elderly women with low body mass index-a populationbased study. Bone 39(2): 385-591.

41. Baker SP, Harvey AH (1985) Fall injuries in the elderly. Clin Geriatr Med 1(3): 501-512.

42. Oh E, Hong GR, Lee S, Han S (2017) Fear of falling and its predictors among community-living older adults in Korea. Aging Ment Health 21(4): 369-378. 


\section{Medical Journal of Clinical Trials \& Case Studies}

43. Lachman ME, Howland J, Tennstedt S, Jette A, Assmann S, et al. (1998) Fear of falling and activity restriction: the survey of activities and fear of falling in the elderly (SAFE). J Gerontol B Psychol Sci Soc Sci 53(1): P43-50.

44. Zijlstra GA, Van Haastregt JC, Van Eijk JT, van Rossum E, Stalenhoef PA, et al. (2007) Prevalence and correlates of fear of falling and associated avoidance of activity in the general population of communityliving older people. Age Ageing 36(3): 304-309.

45. da Costa EM, Pepersack T, Godin I, Bantuelle M, Petit B, Levêque A (2012) Fear of falling and associated activity restriction in older people results of a crosssectional study conducted in a Belgian town. Arch Public Health 70(1): 1.
46. Sattin RW, Easley KA, Wolf SL, Chen Y, Kutner MH (2005) Reduction in fear of falling through intense tai chi exercise training in older, transitionally frail adults. J Am Geriatr Soc 53(7): 1168-1178.

47. Li F, Harmer P, Fisher KJ, McAuley E, Chaumeton N, et al. (2005) Tai Chi and fall reductions in older adults: a randomized controlled trial. J Gerontol A Biol Sci Med Sci 60(2): 187-194.

48. Zhang JG, Ishikawa-Takata $\mathrm{K}$, Yamazaki H, Morita T, Ohta $\mathrm{T}$ (2006) The effects of Tai Chi Chuan on physiological function and fear of falling in the less robust elderly: an intervention study for preventing falls. Archives of gerontology and geriatrics 42(2): 107-116. 